\title{
The Past, Current, and Future
}

\author{
Arthur Michael Michalek ${ }^{1}$
}

Published online: 4 July 2015

(C) American Association for Cancer Education 2015

According to Edgar Rice Burroughs [1], "We are, all of us, creatures of habit," and I am foremost among this group. My days at work invariably begin with the brewing of the first of many pots of coffee, followed by a bowl of cereal while simultaneously reviewing overnight emails and submissions to the Journal of Cancer Education. My daily inbox is, I imagine much like yours, filled with urgent and not so urgent requests, anticipated responses, SPAM, updates of varying importance, and a ragtag collection of posts from various news organizations. One such post from the last category recently caught my attention. It was a story citing an IMS Health report that global cancer drug spending crossed the $\$ 100$ billion threshold in 2014 [2]. (NB: this report is only concerned with cost of cancer medicines and does not include total treatment costs such as direct patient care, radiation, surgery, etc.) This represented an increase of $10.3 \%$ from 2013 and up from $\$ 75$ billion five years earlier. (NB: for thoughts on what is driving these costs, I refer you to a recent NEJM article by Avorn [3]). Spending on cancer drugs represents nearly $11 \%$ of all drug spending globally. IMS forecast is that this will grow to $\$ 147$ billion in 2018. According to GLOBOCAN [4], approximately $11 \%$ of all cancer cases occur in the USA, yet the IMS reports that the USA accounted for $42.2 \%$ of total spending. While I have no doubt that many of these drugs will significantly improve both the quality and length of patient lives, it does give one pause to consider whether given this level of spending on medications we are spending anywhere near enough on cancer education

Arthur Michael Michalek

amm3@buffalo.edu

1 University at Buffalo, Buffalo, NY, USA including training, public education, and direct patient/family educational services.

The Agency for Healthcare Research and Quality (AHRQ) estimates that the direct medical costs (total of all health care costs) for cancer in the USA in 2011 were $\$ 88.7$ billion (11\% due to drugs) [5]. Thus, estimated total care costs for 2013 would approach $\$ 180$ billion. Benjamin Franklin is credited with saying "If an ounce of prevention is worth a pound of cure...." Then, if my calculator is trustworthy and you will permit me some editorial license in my application of some less than rigorous mathematics, it would appear that in the USA, we should be spending approximately $\$ 11$ billion on cancer education/prevention. So reader it is up to you to consider which is the better cost value and which is more palatable, to prevent or to cure? The reality is that at the present time, we need both. I look forward to the day when we have effective prevention strategies for the majority of cancers. When that time comes, we will be challenged with convincing the public to adopt these behaviors. Another email which recently crossed my computer screen was a report in the CDCP Morbidity and Mortality Weekly Report [6] which presented results of a review of 2013 screening rates in the USA. Data demonstrate that “.... around 1 in 5 women are not up-to-date with cervical cancer screening, 1 in 4 women are not up-todate with breast cancer screening, and 2 in 5 adults are not upto-date with colorectal cancer screening." So even when we have effective means of early detection, we will be challenged with engaging the public. As our colleagues in smoking cessation can attest, it takes more than data to change behavior. The need for cancer education and training will then be never more urgently needed.

This past April, I had the privilege to represent the Journal of Cancer Education (JCE) at the annual European Association for Cancer Education (EACE) meeting in Heidelberg, Germany. This was my third EACE meeting, and it only served to reinforce 
the high esteem I hold for the work of our European colleagues. Heidelberg is a charming and vibrant town located along the Neckar River in the southwest portion of Germany. The cobblestone streets of Old Town are lined with quaint shops, sumptuous restaurants, and historic buildings. The Schloss Castle, which began construction in the early thirteenth century, is a marvel to behold. Located over $80 \mathrm{~m}$ above the town, it provides a stunning panoramic view of both the city and the countryside. It also contains the world's largest wine cask capable of holding over 55,000 gallons of wine. The quaintness of Old Town belies the vitality of a vibrant, college town. Heidelberg is home to the oldest university in Germany (founded 1368) and home to nearly 30,000 students. It is also home to the DKFZ German Cancer Research Center, the site of our annual meeting. The German Cancer Research Center (DKFZ) is one of the world's leading biomedical research institutions. The center is staffed by over 3000 individuals including over 1000 scientists. It also houses the Cancer Information Service (KID) which like the CIS in America, upon which it was patterned and developed, "provides cancer patients, their families, and other interested parties with information that is readily understandable, scientifically founded, impartial, and up to date." The DKFZ cancer center is located several kilometers from central Old Town and may be easily walked along Philosophers Way and the bank of the Neckar River. I will avoid a detailed accounting of the many wonderful foods I ate but highly recommend the jagerschnitzel and pilsner.

The EACE meetings remind us that cancer is an international battle. EACE presentations demonstrate how various approaches to cancer education and training are being enacted throughout the world. Our goals are the same, but our battle plans vary in that they must be responsive to both countryspecific systematic and cultural variances. This year's meeting attracted individuals from a dozen countries and three continents. Special thanks go out to President Darren Starmer, Past President Graham Dark, and the Secretariat Sabine FrommHaidenberger, who also delivered the Milly Hagedoorn lecture. This lecture focused on developments in cancer education and within the EACE over the past decade. Space does not allow me to adequately describe this paper nor the many more individual presentations from this year's meeting. One of the greatest impressions that I left with was the assurance that the European commitment to excellence in cancer education and training was quite evident in the presentations of the many students at this meeting. At least eight of the podium presentations were made by students. Students represent the future, and the future of cancer education within the sphere of EACE appears to be quite bright. One of these presentations was given by Bertha Eisses, a medical student from Groningen, Netherlands. She has transformed her EACE presentation into a JCE publication which may be found in this issue [7]. Bertha is a student of Jakob de Vries and performed a clerkship with Shine Chang at the MD Anderson. In her article, Bertha reflects upon the process of arranging an overseas clerkship and the lessons so derived. It is a first-hand account that other students contemplating overseas clerkships may benefit from as well as their mentoring and host faculty. I urge each and every one of you to review her work. We hope to develop a formal section of the JCE highlighting student publications. This will be a discussion topic at the annual editorial board meeting in October at the annual meetings (please visit http://2015.attendicec.org/ to obtain more information). Finally, I wish to share with you some good news that I have recently received from Springer concerning the Impact Factor of the JCE. Last year, the Impact Factor had moved up to 1.054, and this year, we are pleased to announce that it has risen to 1.230 . Congratulations to all the authors and reviewers for making this possible. Let us keep reading and referencing the works published in JCE.

Be well.

Arthur M Michalek, PhD, FACE

\section{References}

1. Edgar Rice Burroughs, The beasts of Tarzan

2. IMS Health finds global cancer drug spending crossed $\$ 100$ billion threshold in 2014. www.theimsinstitute.org

3. Avorn J (2015) The $\$ 2.6$ billion pill — methodologic and policy considerations. N Engl J Med 372(20):1877-1879

4. International Agency for Research on Cancer. http://globocan.iarc.fr/ Pages/fact_sheets_cancer.aspx

5. Agency for Healthcare Research and Quality. http://www.ahrq.gov/

6. Cancer screening test use-United States, 2013, CDC, Morbidity and Mortality Weekly Report, accessed 13 May 2015. Morbidity and Mortality Weekly Report

7. Eisses B, de Vries J, Chang S (2015) Reflections on a research clerkship abroad. J Cancer Educ 